\title{
Social Media as Support for Partners of Veterans With Posttraumatic Stress Disorder
}

\author{
Susan L. Ruiz \\ Walden University \\ Lee Stadtlander \\ Walden University
}

\begin{abstract}
Researchers have established that partners of veterans who isolate socially because of posttraumatic stress disorder are also socially impacted. It is not known how partners cope with their own social isolation and the influence of social media on the isolation while maintaining commitment to their veteran partners. Weiss' theory of the syndrome of loneliness was used as the basis for this phenomenological study investigating social experiences in 10 female participants drawn from social media groups. Although the study was open to male or female partners, only female partners of male veterans chose to participate. Qualitative email interviews established how the participants socialized as well as the professional and supportive services they might consider beneficial. Data were coded and analyzed to identify patterns that emerged from the experiences of the participants. The primary themes that emerged included that the women had established deep commitments to their veterans and experienced social isolation. Participants' perception of the social stigma of posttraumatic stress disorder resulted in social withdrawal and a dependency on social media for their social interaction and support.
\end{abstract}

Keywords: posttraumatic stress disorder, social experiences, social isolation, loneliness, committed relationships

\section{Introduction}

During military combat, soldiers often experience horrific events first hand, which may result in posttraumatic stress disorder (PTSD). PTSD is defined as the development of specific symptoms caused by exposure to a traumatic event such as witnessing the injury or death of another person or experiencing the threat of personal injury or death (American Psychiatric Association, 2013). The fifth edition of the Diagnostic and Statistical Manual of Mental Disorders (American Psychiatric Association, 2013) details additional criteria that is presently used to diagnose PTSD; however, in the present study, the veterans were diagnosed with PTSD under the previous edition of the Diagnostic and Statistical Manual of Mental (fourth edition, text revision; American Psychiatric Association, 2000). Veterans with PTSD typically experience the symptoms of anger, mood changes, hyperarousal, emotional numbing, social isolation, and difficulties in their marital relationships (Taft, Street, Marshall, Dowdall, \& Riggs, 2007). Veterans' symptoms may affect their partners and children (Dekel, Goldblatt, Keidar, Solomon, \& Polliack, 2005). In the present study, female partners of veterans with PTSD shared their experiences with social media, social isolation, and their veteran.

Please address queries to: Lee Stadtlander, 25 Morgan Creek Lane, Bozeman, MT 59718. 
Social isolation is a commonly reported and researched symptom for veterans suffering from combatrelated PTSD (Blake et al., 1990; Hofmann, Litz, \& Weathers, 2003; Solomon \& Dekel, 2008). This isolation often extends to the partner or spouse who becomes socially isolated because the veteran has difficulty socializing, does not want to be left alone, and may be controlling of the partners' activities (Dekel \& Solomon, 2006; Sherman, Perlick, \& Straits-Tröster, 2005).

Partners are often required to have a dual role: that of wage earner and of caregiver. Caring for a partner who has suffered psychological injury during deployment can be both stressful and challenging (Matsakis, 1996, p. 217). A recent option for help and support is through online support groups in social media, such as Facebook. Online peer-led support groups have been reported to offer a sense of well-being, control, self-confidence, and personal empowerment in many individuals who use them (Barak, Boniel-Nissim, \& Suler, 2008). However, research has not determined how social media affects isolation in partners of combat veterans with PTSD; the present study examines this issue.

\section{Partners of Veterans With PTSD}

Partners of veterans diagnosed with combat-related PTSD face complex issues that set them apart from partners of veterans without this diagnosis (Monson, Taft, \& Fredman, 2009). Prior to a veteran's deployment, many partners shared household responsibilities, and together they maintained social contact with friends and family (Drummet, Coleman, \& Cable, 2003). Combatrelated PTSD often results in substantial changes in the veterans' normal function, which interferes with their ability to share the same household responsibilities. Partners often find that they must function as the financial provider and caregiver for their veteran and family (Arzi, Solomon, \& Dekel, 2000).

In addition to the added burden of financial and social responsibilities, partners of veterans with PTSD are exposed to the psychological and physical changes in their veterans. These partners are the closest targets to the veterans who may have anger issues, mood changes, or violent tendencies (Taft et al., 2007). Previous researchers examining partners of veterans with PTSD have suggested the concept of secondary traumatization, known as compassion fatigue or vicarious trauma, to explain the psychological effect of repeated exposure to another individual's traumatic events (Arzi et al., 2000; Bride \& Figley, 2009; Dekel \& Solomon, 2006). Researchers have suggested that through secondary traumatization, partners are at risk of experiencing psychological symptoms similar to their veteran partners: depression, anxiety, guilt, and distressing dreams (Dekel et al., 2005; Renshaw et al., 2011). In addition, partners of veterans with PTSD often find themselves socially and emotionally isolated, resulting in loneliness (Dekel et al., 2005). Partners may find themselves isolated from the veteran, as he retreats from interaction. Boss and Couden (2002) described this condition of the veteran being physically present but psychologically absent as ambiguous loss for the partner.

In the current study, female partners of veterans described the impact of the veterans' PTSD on their own social experiences. The primary purposes of the current study was to explore (a) how participants describe their social media and other social experiences and how their experiences are related to loneliness, (b) participants' reports of satisfaction with their social experiences and the effect on loneliness, and (c) experiences with professional and community services. 
Ruiz \& Stadtlander, 2015

\section{Professional Services and the Veteran's Partner}

Researchers have advocated for professional services, particularly family and marital counseling, for partners of veterans with PTSD since the Vietnam War (e.g., Galovski, \& Lyons, 2004; Jordan et al., 1992). However, there has been little research on the professional services actually desired/wanted by partners of veterans with PTSD. The current study addresses this issue through questions concerning professional services desired by the partner.

\section{Social Media and Support}

Self-help (or peer-led) support groups have existed online since the 1980s. During this time, online support groups, also referred to as e-groups, forums, listservs, bulletin boards, and mail groups, have quietly woven themselves into the Internet community and become a common resource for almost every medical, psychological, and social problem (Lorig et al., 2010). Self-help support groups rely on individuals to provide asynchronous general, emotional, and social interaction, and information to one another, generally without a professional's intervention or guidance (Barak \& Grohol, 2011). Online peer-led support groups have been reported to offer a sense of well-being, control, selfconfidence, and personal empowerment to many individuals (Barak et al., 2008).

Researchers (e.g., Barak, \& Grohol, 2011; Lorig et al., 2010) have examined the effects of support groups on caregivers of dementia and mentally ill individuals' caregivers. When participating in online support groups, caregivers show statistically significant reductions in caregiver burden, depression, pain, and stress (Lorig et al., 2012). Previous research has not examined the benefits of informal online support groups for caregiving partners of veterans with PTSD. Previous research has also not examined whether the support and interaction offered in such groups influences the perception of loneliness. These topics will be explored in the current study.

\section{Weiss' Theory of Loneliness}

Loneliness is "a state in which a discrepancy exists between the interpersonal relationships one wishes to have and those they perceive to have" (Heinrich \& Gullone, 2006, p. 698; Peplau \& Perlman, 1982). Changes in the individual's social relationships or their perceived needs or desires for social relationships are believed to trigger the development of loneliness (Peplau \& Perlman, 1982). Additionally, Weiss (1973) proposed that the syndrome of loneliness was the product of emotional isolation (i.e., an individual's lack of emotional engagement to those closest to them) and social isolation (i.e., lack of social contacts that provide companionship, friendships, or any other meaningful relationships). According to Weiss, individuals devoid of these meaningful relationships could exist in a state of loneliness. Spouses of veterans with PTSD may dismiss their own social relationships in order to support the veteran who isolates socially (Solomon \& Dekel, 2008); it is important to identify the presence of, and to what degree the spouse believes she is affected by, loneliness. If the current study finds that spouses perceive they are devoid of satisfying interpersonal relationships, future research may be able to target specific interventions to support the well-being of the spouse and not just the veteran.

The present study used Weiss' theory of loneliness as a framework for creating questions and as an interpretative tool for understanding participants' descriptions of their social and emotional experiences. Although partners of veterans with PTSD have reported experiencing loneliness (Galovski, \& Lyons, 2004; Solomon \& Dekel, 2008), the type of loneliness they felt is not clear. Partners may perceive their own loneliness to be emotional (lack of an adult attachment to their 
Ruiz \& Stadtlander, 2015

veteran) or social isolation (lack of communication with family and friends) or both. With the improvements in technologies and social media that bring communications to a larger audience, it is also not clear if partners of veterans with combat-related PTSD still exist in a state of loneliness. In the current study, these issues are explored through an analysis of how the participant describes their relationship to the veteran (emotional attachment) and to others (social isolation). Of particular interest will be their use of the words "lonely" and "loneliness."

\section{Method}

This study employed a phenomenology method to develop a comprehensive description of the impact of social media on social isolation and loneliness in partners of veterans with PTSD (Creswell, 2007). This qualitative research method was selected because it offered a deeper understanding of how the partners of veterans with PTSD experience the phenomenon of social isolation and loneliness. Because there are many available supportive resources for the veteran, this study chose specific questions developed just for the spouses. Although it is conceivable that spouses also need support resources to maintain individual well-being, these exact resources have not been previously clearly defined. The specific research questions were developed through an examination of the literature and to address gaps as to how spouses use social media and to identify their individual needs for support services. Three research questions guided the study:

Research Question 1: How do participants describe their social media and other social experiences in light of the veterans' social isolation due to PTSD? How are their experiences related to Weiss's (1973) theory of loneliness?

Research Question 2: How do partners of veterans with PTSD describe their satisfaction with their social experiences? How are their experiences related to Weiss's (1973) theory of loneliness?

Research Question 3: What do partners believe they need from professional and community services to be supported?

The present study recruited 10 female participants who met the inclusion criteria. Although the study was open to male or female partners, only female partners of male veterans chose to participate. The inclusion criteria for the study were (a) the veteran must have a diagnosis of combat-related PTSD, (b) the partner must have lived with the veteran for a minimum of 1 year, (c) the veteran has experienced problems socially and prefers to isolate, and (d) the participant was not actively engaged in professional counseling services. The decision to not include participants engaged in professional counseling services was made (a) to eliminate counseling as a mechanism to decrease loneliness, (b) not to distract the spouse from the purpose of the counseling, and (c) to not tax the spouse beyond their participation in counseling to participate in this study. Participants were currently or within the past 5 years married to or resided with a combat veteran, separated or divorced, or a widow of a combat veteran with PTSD. Eligible participants included partners of veterans from all war theaters from Vietnam to the wars in Iraq and Afghanistan. The exclusion criteria were that the participant is actively engaged in professional counseling services and did not meet the inclusion criteria. No inclusion criterion was integrated concerning comorbidity or traumatic brain injury in the veteran, one partner mentioned the presence of traumatic brain injury (J3, age 30, married, time with veteran: 8 years). 
This study was approved by the sponsoring institution's Institutional Review Board. In addition, a broad approval to conduct the study was received from the Department of Defense, the Department of the Army, and the Department of Veterans Affairs (VA).

Recruitment took place in two online Facebook groups for spouses of veterans' with PTSD; the interviews were then conducted through email interviews (Merriam, 2009). The group managers (i.e., individuals who set up and maintain the groups) on Facebook posted the recruitment flyer to their Facebook page. Using the email address created for this study, interested group members contacted the researchers by email. Initial study information and participant criteria were forwarded to each individual. Upon receipt of the responses to the study criteria, all interested individuals who met the criteria were emailed the consent form, a brief demographic survey, and qualitative questions (see Appendix). Participants were reminded that they could withdraw at any time and that all information provided would be kept confidential. Participants responded through a secure email address established for this study and they were identified in all study materials by the first letter of their first name and a number from 1 to 10. Each participant was asked to respond to identical questions to describe how they socialize and how they interact with the veteran during their socializing. As a supportive measure for the participants, each participant was given the contact information for support hotlines.

There was no monetary compensation for participation in the study. The data collection continued until the study reached saturation in which no new information was provided (Moustakas, 1994). Ten women met all the criteria to be eligible to participate in this study; all were members of a Facebook group. Participant demographics were collected only for descriptive purposes and are provided in Table 1.

Table 1: Participant Demographics

\begin{tabular}{lccccc}
\hline Identifier & Age & Marital Status & Education & Employment & $\begin{array}{c}\text { Years with } \\
\text { Veteran }\end{array}$ \\
\hline C1 & 34 & M & 3 years college & VA Caregiver & 2 \\
C2 & 44 & M & Bachelor's degree & Education & 6 \\
& & & & & \\
J3 & 30 & M & 3 years college & Homemaker & 8 \\
J4 & 29 & $\mathrm{~S}$ & High school diploma & VA Caregiver & 6 \\
K5 & 23 & M & Bachelor's degree & Medical receptionist & 3 \\
M6 & 26 & M & Technical school & Human resource & 8 \\
& & & manager & 31 \\
N7 & 54 & M & Technical school & Self-employed & 4 \\
R8 & 25 & $\mathrm{~S}$ & Certification program & Desk job and driver & 7 \\
V9 & 30 & M & Bachelor's degree & Recruiter & 3 \\
A10 & 43 & M & 3 years college & VA Caregiver & 3 \\
\hline
\end{tabular}

Note. $\mathrm{VA}=$ Veterans Affairs; $\mathrm{M}=$ married; $\mathrm{S}=$ single. 
Ruiz \& Stadtlander, 2015

\section{Data Analysis}

\section{Epoche}

According to Moustakis (1994), the researcher is the primary instrument in phenomenological research. As the primary instrument, the primary researcher employed the first step in phenomenological reduction, epoche, to identify and effectively manage any potential bias and to reflect the experiences and beliefs of the participants only (Moustakis, 1994). Using epoche to set aside the researcher's experiences and beliefs established the basis to appreciate the experiences and beliefs of spouses and partners who deal with PTSD every day. This approach purposefully withheld any contributory experiences, beliefs, or opinions of the researcher.

\section{Horizonalization}

The next step in phenomenological reduction is horizonalization of the data (Creswell, 2007). In horizonalization, every statement is viewed with equal value, and every statement then becomes a new horizon in which a fresh idea emerges from the data (Moustakas, 1994). Each participant response was coded to reflect the similarities and variations in data from which the dominant themes for this study emerged or were composed. The data provided in the interviews was then compiled for comparison between the participants. Similarities and distinctions among all participant experiences were identified and examined.

\section{Discrepant Case Analysis}

Discrepant cases, as defined by Creswell and Plano Clark (2007), are cases that do not reflect the same data as all the other cases do. Nine of the participants in this study had experienced changes in their social interaction due to their veteran's PTSD, and their experiences were in agreement. One participant, however, described having her social experiences dictated by the veteran and engaging in the escape of alcohol; this was considered to be a detriment to her social life reported in the current study.

\section{Results}

Three participants assumed a 24-hr position within the home as a VA caregiver. The VA Caregiver program, managed by the Department of VA, was created to support spouses of veterans with PTSD; the spouse provides the extensive care in the veteran's home (Amdur et al., 2011). This program offers respite services and monetary compensation to the spouse for this service to the veteran. In this additional role, the participants described an extremely limited or nonexistent social relationship with anyone other than the veteran, except for their social contacts through Facebook. Participants who logged onto Facebook found other caregivers who had similar issues and were supportive.

Participants were divided in their appraisal of social interactions: Five participants reported that their social lives were extremely unsatisfying. Five participants, however, reported being completely satisfied with their current social life. Family and friends were described by participants as having a limited understanding of their life with PTSD, and most participants described feelings of frustration about the perceived judgmental attitudes of everyone outside of the immediate veteran's home. In some cases, participants described their life with the veteran as one devoid of social interactions other than those found through social media. Despite the availability of online contact with others, participants in the current study expressed specific social issues that are summarized through three themes. 
Ruiz \& Stadtlander, 2015

\section{Research Question 1: How Do Partners Describe Their Social Experiences in Light of the Veterans' Social Isolation Due to PTSD?}

The participant responses were carefully examined, and Theme 1 emerged: My social life: A limited existence. Participants described the impact social isolation in their veteran with PTSD had on their own social experiences. From the responses of the participants, the common thread was that their social lives had changed, and the limitations to their social life with family, friends, and the community were due to the veterans' PTSD issues. Excerpts from these responses follow:

His isolation affects the whole family. For me if we are at family gatherings I am normally left by myself. We have two girls and I am left making sure they are taken care of while he is isolating himself. I hate the looks I get from people that don't or refuse to understand that he isn't there with me because he doesn't want to. Although at times it feels like he would rather be alone then be with us. I hate it. At times, I resent that fact that he leaves me all alone at gatherings. It feels like he would rather be anywhere as long as it isn't with me. We do not have friends that come to the house. He can't handle having more people in our home. I have become more isolated myself. I no longer want to try to explain why he isn't around and is isolating himself. (J3, age 30 , married, time with veteran: 8 years)

Because he needs someone to care for him, I have to be here and don't get many chances to go out alone. (J4, age 29, single, time with veteran: 6 years)

He cannot be left alone- - he turns on the gas stove and it sometimes blows out filling the house with gas-he wants to beat up strangers when we have to shop for food-I wish I could order groceries online. When he has an episode where he can't stop shaking and curls up he cannot control himselfthis scares people—because he looks "normal" ... we suffer looks and stares in public-it is painful for us both and our children are embarrassed and are too young to understand. (A10, age 43, married, time with veteran: 3 years)

\section{Research Question 2: How Do Partners of Veterans With PTSD Describe Their Satisfaction With Their Social Experiences?}

Five of the 10 participants described being dissatisfied with their social life. The remaining five participants responded as being satisfied with their social lives. Ultimately, from the participants' descriptions, it was found that partners of veterans who were determined to remain committed to their veteran did so, but at the expense of their social life. Participants who were struggling to maintain their social life found their relationship with the veterans to be strained. Overall, participants desired a social life that included the veterans; however, in the current study, participants were limited to socializing with others during children's activities, socializing alone, or choosing not to socialize at all. Participant responses that described their satisfaction with their social experiences were examined, and Theme 2 emerged as Committed to the Veteran: Socializes Alone. Excerpts from the responses follow:

It stinks. We used to be very social, very active in the community, go to other people's houses for dinner, or for poker games or just to hang out at a bonfire. Now he doesn't want to do any of that, so it limits what I get to do. He also 
Ruiz \& Stadtlander, 2015

doesn't want to go to new places or anywhere where there is a crowd. (C2, age 44, married, time with veteran: 6 years)

My social life is non-existent right now. I am actually very unsatisfied with it. (J4, age 29 , single, time with veteran: 6 years)

I am pretty lonely sometimes ... mostly when his symptoms are worse and he can't bring himself to leave the house. When he's really bad, he can't leave the bedroom because the noise of the kids and animals and the light are too much for him to take. When he is having a good couple of days, we try to get out of the house for a few hours. (C1, age 34, married, time with veteran: 2 years)

Participants indicated that their socializing was limited to those related to children's activities, socializing alone, or choosing not to socialize at all. One veteran accompanied his partner to social events; the participant described being able to socialize with the veteran because she already knew where he would prefer to sit. She described that they found that setting boundaries and communicating together made it possible for them to socialize. However, two other participants described attending events with their veteran whereby the veteran would withdraw from them and from others at the event. Despite having the opportunity to socialize with the veteran, the latter two participants described feeling that they still socialized alone. Participants defined this condition of "socializing alone" as the act of socializing with the veterans who cannot connect with others during the time they are out, or the act of socializing away from home without the veterans. The remaining five participants expressed a deep dissatisfaction with their social life: The participants predominantly believed this to be due to the veteran not accompanying them to social events or activities. Participants described their increased use of social media as a viable option to connect with others. One participant described feeling "lonely"; however, none of the participants described their present situation in terms of loneliness.

For some participants, having family contact was based on the distance the veteran couple would need to travel in order to attend events or activities. For some, the only means of communicating with family was by phone call, texting, or through social media. The primary reason stated for this was due to the perception that family and friends were judgmental or were unable to understand the veteran's issues with PTSD. For two participants, contact with family was dependent on the agreement of the veteran to permit a visit to the home. For example, in one case, parents of the participant were permitted to visit but they needed to call first. By doing so, they were assured that the veteran would be able to participate in the visit. For others, family socializing was limited to occasional trips to a local restaurant where the veteran was comfortable. In this setting, the participant would often act as a buffer between the family and the veteran; the partner described a lack of sensitivity in family members who either chose not to understand PTSD or chose to exhibit a judgmental attitude towards the veteran couple. In this instance, the partner then maintains a selfappointed position of "buffer" or "guard," and she is compelled to explain unusual situations and behaviors either for the veteran or as it relates to the veteran. Subsequently, some partners felt the perceived lack of understanding and judgmental attitude to be a significant reason to withdraw from social contact with family. Despite the decision to do so, some participants expressed a loss of this attachment to family but knew of no viable way to rectify the situation. Only one participant described their family support as one of understanding and available when the need arose. 
Ruiz \& Stadtlander, 2015

Friends of the participants were often described as maintaining a judgmental attitude when the veteran chose not to accompany the partner to social events or activities and the veteran was, in turn, critical of the friends. Participants frequently reflected on what their social life used to be, before the veteran's PTSD issues arose. The descriptions provided by the participants in the current study echoed a sense of loss, which could be explained as a loss of social and familial attachments that the partner was not ready to do without. Some participants described a consistent social life with friends in which they would met in public locations with their veteran, but insisted that they were tired of having to explain the veteran's PTSD issues to friends. Additionally, participants believed that a social stigma regarding PTSD existed and that their friends did not understand or support their relationship with the veteran.

\section{Research Question 3: What Do Partners Believe They Need From Professional and Community Services to Be Supported?}

Professional and supportive services are those entities that provide safe avenues for individuals needing assistance in some area of their life, for example individual, marital, or family therapy. For the spouses of this study, support services were thought of as professional services with a therapist or counselor or the support found among family and friends. Available research into how spouses of veterans access professional and support services was represented in the study as a gap in the literature. Newer research has focused more on active duty spouses versus the spouses of veterans. Current literature has not adequately evaluated how spouses of veterans with PTSD access professional and support services. In the present study, spousal descriptions of a lack of support by family and friends, and their own distress over changes in their committed relationship with the veteran, described a lack of effort on their part, in seeking professional or supportive services, and Theme 3 emerged as Assisting the Veteran Partner: The Benefits of Seeking Professional and Support Services. The following is an excerpt of a participant's beliefs regarding using services and what services she would choose:

I have not considered seeking professional help in the last year. I have had others things to worry about. I hardly take care of myself ... If there was someone in the area that understood then I might go see them. The last person I saw told me to suck it up and deal with it ... If there was a support group for spouses dealing with it I would go. There is none in the area ... Only closed/private groups on Facebook. There aren't any groups in my area . .. The only support groups that I have used are on Facebook. They help to a point. I hate trying to type everything that is going on and how I am feeling. It would be better if I could go to one in person or could talk someone that has dealt with this in person. (J3, age 30, married, time with veteran: 8 years)

Participants expressed that they had considered professional and support services; however, eight participants had either not initiated contact to acquire such support, or the services are not available in their geographical area. Two participants sought professional or support services and were dissatisfied. None of the participants was actively using professional services at the time of this study (as stipulated in the inclusion criteria), and those who had used professional services had not done so in the previous year. Finally, some partners expressed a lack of interest in attending support sessions because the veteran would be uncomfortable attending the support sessions with the partner, or they themselves are not comfortable in group settings. Interestingly, in considering the level of perceived discomfort during the professional or group support session, these participants did not consider their own individual needs for using professional services alone. 
Ruiz \& Stadtlander, 2015

\section{Discussion}

The current study has provided compelling personal accounts on a previously unexplored topic: informal social media support groups as a method to reduce the loneliness and isolation in spouses of veterans with PTSD. Given the ubiquitous nature of social media, the opportunities for utilizing it as a mechanism for social support are unlimited and just beginning to be realized, particularly for the socially isolated.

This study mirrors to a large extent, the findings of earlier studies whose goal was to understand what it meant to live with a veteran with PTSD. In previous studies, issues of caregiver burden, secondary traumatization, social and emotional isolation were described by spouses of veterans with PTSD and the current study found that these issues tend to continue (Dekel et al., 2005; Dirkzwager et al., 2005). Earlier research, however, could not consider the VA Caregiver program initially offered through the Department of VA in May 2011 (Amdur et al., 2011). Additionally, earlier research did not address the use of social media among study participants. In the current study, nine of the 10 participants had been with their veteran fewer than 8 years, and the remaining participant has been married to the veteran for 31 years. Some partners, however, had only been married or in the committed relationship for a few years, which was after the veteran had served on active duty. These partners had no relationship with the veteran before the veteran's military service. Subsequently, the partners could not compare the relationship before and after the veteran's military service.

\section{Research Question 1: How Do Partners Describe Their Social Experiences in Light of the Veterans' Social Isolation Due to PTSD? How Are Their Experiences Related to Weiss's (1973) Theory of Loneliness?}

In previous studies, partners of veterans with PTSD expressed concerns over a lack of social connection with others (Klarić et al., 2009). The current study found that the same partner concerns continue, particularly when interacting with friends and family in-person, consistent with social isolation (Weiss, 1973). However, a new concern was identified in partners who have been designated as VA caregivers: providing 24-hr care to their veteran restricts their opportunities to socialize outside the home. These partners described themselves as becoming as socially isolated as the veterans are, having clear feelings of isolation, and suffering depression themselves. Future interventions and research into satisfying social relationships for VA Caregivers appears to be needed in order for the spouse to maintain psychological wellness.

Weiss (1973) postulated that individuals who were devoid of satisfying social networks were socially isolated, and this contributes to the syndrome of loneliness. The description of in-person interactions given by participants in the current study align with this theory and according to Weiss, this syndrome would continue until social networks were reestablished. However, previously, the use of Internet support was not available to be considered.

Participants described that the majority of their social contacts were obtained through social media. It appears that this access to others primarily through social media could be considered a lifeline for partners of veterans with PTSD. However, social media may also provide an excuse to not pursue other in-person social connections. They may find that their social needs are being met, and there is no need to pursue other avenues. Thus, when considering Weiss's (1973) theory of loneliness, there appears to be a need to extend the theory, as illustrated in the present study, to accommodate both in-person social interaction and Internet social interaction. In the current study, the participants' in- 
Ruiz \& Stadtlander, 2015

person social needs appeared to be insufficient, while their Internet social needs were sufficient in reducing feelings of isolation and loneliness. Future research that evaluates the use of social media as the primary or only source of socialization is needed.

\section{Research Question 2: How Do Partners of Veterans With PTSD Describe Their Satisfaction With Their Social Experiences? How Are Their Experiences Related to Weiss's (1973) Theory of Loneliness?}

It is logical that each participant had a social life prior to their committed relationship and, to some degree, found satisfaction with it. At the time of the marriage to the veteran, it is also conceivable that the participants' friends and family had limited understanding of PTSD, and the participants may have entered into the relationship with, or without, the blessings and well wishes of family and friends. One participant in the study described her disengagement with family and friends once she married the veteran simply because they had become judgmental, and the relationship with them had become strained to the point where it was better for the participant to let the relationship go. The participant was not forced to choose this (by veteran or the family), but she chose to disengage from family.

In considering Weiss' theory of loneliness (1973), the emotional attachment to the veteran appeared to be present, although altered in many cases from the precombat relationship. The loss of participants' in-person social contacts with family and friends does suggest a degree of social isolation.

The study found that only five of the 10 participants were satisfied with their social life. Three participants who felt satisfied with their social life also described having emotional attachments to friends, and the time spent socializing was enough to offset any perceptions of boredom that Weiss (1973) postulated as a facet of social isolation. The second half of Weiss' (1973) bimodal model for the syndrome of loneliness, social isolation, became evident through the analysis in their reported experience of losing social attachments. When participants described negative changes to their social life with the veteran, it became evident that to make the relationship work, they needed to find satisfying attachments to substitute for the adult attachments that they no longer had among family and friends. It appears that many of the participants found satisfying attachments through their social media support. Future research that appraises both components of social interaction-inperson and through social media among a larger population of partners of veterans with PTSD—may be able to identify areas for the development of interventions that address the need of participants.

Two participants described how they and their veterans were stared at and negative comments were directed towards them when out in public. The participants expressed that this reaction and unfair treatment was a "social stigma." As a result, they expressed their feelings of seclusion and becoming as socially isolated as their veteran did; these findings are similar to those reported by Dekel et al. (2005). In considering this further, it is possible, then, that the social stigma perceived by the participant is more of a disapproval of the relationship or a lack of education, leading to the attitudes directed to the couple when they were in public, which is interpreted by the participant as a social stigma. Partners expressed the need to maintain a self-appointed position of "buffer" or "guard"; feeling compelled to explain unusual situations and behaviors either for the veteran or to others about the veteran, which further distances them from others. In contrast to previous research (e.g., Outram, Hansen, Macdonell, Cockburn, \& Adams, 2009), only one participant described her social life as being dictated by the veteran. Future research with a larger sample could evaluate the 
presence of dominating behaviors by the veteran towards the spouse in the committed relationship and the degree of impact it has on the spouse's overall social experiences.

\section{Research Question 3: What Do Partners Believe They Need From Professional and Community Services to Be Supported?}

Two participants described experiencing depression, and one of these participants described an increasing use of alcohol. Other participants described feeling sad, angry, and withdrawn from family and friends, consistent with secondary traumatization (Dekel et al., 2005). These participants stated that they considered, but had not pursued, the use of professional or social interaction. If the use of professional or support services was viewed as a tangible method to improve their quality of life, it is remarkable that the participants have not pursued this option. Participants were willing to attend professional or support services as a couple, if the veteran was comfortable while attending with the partner. Those participants who would seek professional services would do so for the veteran's needs rather than their own. Thus, the individualized assessment of their own psychological well-being was not described as a personal need but one that could benefit the couple.

According to Weiss (1973), in instances of grief, the individual who exists in the condition of loneliness is experiencing a reaction to the absence of the loved one versus the loss of a loved one. Dekel et al. (2005) described this as ambiguous loss. Ambiguous loss has been defined in this study as the physical presence of a loved one who is psychologically absent (Boss \& Couden, 2002). Social isolation is an inherent aspect of PTSD (American Psychiatric Association, 2000); when the isolation extends to isolation from the partner, it can be interpreted as ambiguous loss. Three participants in the current study mentioned their memories of socializing with their veteran before PTSD. It is likely that the study participants, who described these memories of the veteran in this manner, are indeed struggling with ambiguous loss. Future research that examines the presence of ambiguous loss in the veteran relationship may be able to identify the coping skills employed by the partner of the veteran and to develop interventions and treatment modalities that will aid in sustaining the relationship.

In summary, the study's partners of veterans with combat-related PTSD were impacted to some degree by the symptom of social isolation of the veteran. The phenomenon of social isolation in the partner was found to some degree in all participants in the present study. The effect of the phenomenon was influenced by factors such as acceptance and socialization with the family and friends of the partner. For many participants, this limited association with friends and family served as a catalyst in which participants chose to voluntarily seek social connections online. Partners in the present study chose Facebook as a socialization venue where they felt accepted and supported.

Although it is conceivable that participants in this study have experienced situations that contributed to their present condition of social isolation, only one participant specifically mentioned feeling lonely (Subject C2, age 44, married 6 years), she indicated that she uses the Internet exclusively for connecting with friends and family. Thus, for her, social media appears to be providing an adequate social support at this time. Some partners also chose to retain previously established adult attachments and work to educate others regarding the effect of PTSD on the veteran and on the committed relationship. For those who chose attachments that offered frequent social contact, the time spent with family and friends appeared to offset the impact PTSD had on them. In contrast, partners who chose not to obtain and maintain adult social contacts, the limitations on their social life resulted in feelings of dissatisfaction. For some, this dissatisfaction was not enough to prompt participants to seek professional and support services primarily due to a 
lack of self-perception that they themselves would benefit from these services. It is also conceivable that these partners avoided professional support because they could not accurately define their own condition of loneliness well enough to seek these services.

A limitation of the current study was that the study participants were all recruited through social media; thus, the results may not be generalizable to the general population of veteran spouses. Individuals participating in social media support may have personality characteristics or social needs that differ from individuals who do not seek out such social interaction.

Another limitation to this study was that the study could not progress unless the participants addressed the study questions through email. Other limitations to this study were that the potential for participants to have diverse opinions and perceptions, due, in part, to a broad range in participant ages and length of time in the committed relationship. The age range was not specifically defined for this study. The oldest participant in this study was 54 years of age and the youngest participant was 23 years of age. Additionally, the oldest participant had been married to the veteran for 31 years. However, the variance in participant age, as well as the amount of time in the committed relationship with the veteran, could be viewed as a potential advantage because different coping skills and methods utilized by partners to work through issues related to their veterans PTSD symptoms came to light.

\section{Future Research Recommendations}

Participants for this study were female spouses of male veterans with PTSD. Due to the small size of this study, and that there were no male spouses of female veterans with PTSD, future qualitative research is warranted that includes both genders. This may deepen the understanding of how spouses of veterans with PTSD find support through their social experiences and through social media and how they may be better served. Future research that evaluates the use of social media as the primary or only source of socialization is needed.

Large-scale qualitative research is warranted to explore the psychological well-being of spouses who serve as VA Caregivers and who have limited, or nonexistent, social contacts. The Department of VA's telemedicine program, currently used by the veteran, could potentially expand to benefit the VA Caregivers who spend the majority of their time at home with their veteran. By including the VA Caregivers in the telemedicine/telepsychology services, providers would be positioned to provide timely advice and care to partners who might otherwise avoid seeking any professional or support services. Successfully supporting the psychological well-being of the partner/spouse of a veteran with PTSD could also influence the services rendered for other populations such as the partners and spouses of law enforcement, emergency medical technicians, and firefighters diagnosed with PTSD.

Companies that develop Internet platforms could potentially develop and market software that affords the privacy and confidentiality to clinical providers who could extend therapies to populations that before social media would have not become engaged. In so doing, populations that were previously uncomfortable in group settings would be able to benefit from the clinical access to providers trained to work with these and other issues. Insurance companies should consider the tremendous benefit to a potentially large population who would use online and telepsychological services and find avenues to provide coverage for care.

Providers of psychological services are in a position to develop therapies that address the need of spouses and partners of veterans with social isolation issues. The influx, and ease, of access to the 
Internet could be considered a viable tool to connect with those who would not, or could not, engage in therapy otherwise. The study suggests there is an opportunity for mental health professionals to reach potential clients through social media. However, because partners of veterans with PTSD appear to have difficulty in recognizing their own needs for professional help, mental health professionals may be best served by phrasing such help in terms of the veteran, for example, "Living with the PTSD veteran."

\section{Conclusions}

This study examined the lived experience of partners of veterans with PTSD recruited through social media. The results indicate a strong reliance by the participants on social media to reduce their social isolation. Weiss's (1973) theory of loneliness predicted there would be more loneliness evident in the sample than was found, due to their reduced in-person social interactions with friends and family members. The study suggests an extension of Weiss's theory is needed to accommodate the social interaction now available through the Internet.

The participants reported a strong commitment to the veteran despite their isolation, evidence of Weiss's emotional engagement. However, the partner commitment tended to result in isolation from family and friends. One relationship was described as having 31 years' longevity, and it is possible that the participant knew her veteran during his military service prior to his diagnosis of PTSD. This participant described working through the changes that have evolved during and since the diagnosis of PTSD. Additionally, this participant was significantly older than the remaining sample in this study; she also appears to have the richest social interaction. Rather than sacrificing the relationship because of significant stresses related to PTSD in the veteran, the participant developed a consistent working and reworking of boundaries through communication with the veteran.

The participants showed a consistent lack of utilization of in-person mental health professional support; however, their reliance on social media shows an opportunity may be available for professionals to reach them through this venue. Participants did not tend to consider their own mental health needs and only thought of professional services in terms of their veteran partners.

\section{References}

Amdur, D., Batres, A., Belisle, J., Brown, J., Cornis-Pop, M., Mathewson-Chapman, M., .. . Kennedy, P. (2011). VA integrated post-combat care: A systemic approach to caring for returning combat veterans. Social Work in Health Care, 50, 564-575.

doi:10.1080/00981389.2011.554275

American Psychiatric Association. (2000). Diagnostic and statistical manual of mental disorders (4th Ed., text revision). Washington, DC: Author.

American Psychiatric Association. (2013). Diagnostic and statistical manual of mental disorders (5th Ed.). Washington, DC: Author.

Arzi, N. B., Solomon, Z., \& Dekel, R. (2000). Secondary traumatization among wives of PTSD and post-concussion casualties: Distress, caregiver burden and psychological separation. Brain Injury, 14, 725-736. doi:10.1080/026990500413759

Barak, A., Bonil-Nissim, M., \& Suler, J. (2008). Fostering empowerment in online support groups. Computers in Human Behaviors, 24, 1867-1883. 
Barak, A., \& Grohol, J. M. (2011). Current and future trends in Internet-supported mental health interventions. Journal of Technology in Human Services, 29, 155-196.

Blake, D., Keane, T., Wine, P., Mora, C., Taylor, K., \& Lyons, J. (1990). Prevalence of PTSD symptoms in combat veterans seeking medical treatment. Journal of Traumatic Stress, 3, 15-27. doi:10.1002/jts.2490030103

Boss, P., \& Couden, B. A. (2002). Ambiguous loss from chronic physical illness: Clinical interventions with individuals, couples, and families. Psychotherapy in Practice, 58(11), 1351-1360. doi:10.1002/jclp.10083

Bride, B., \& Figley, C. (2009). Secondary trauma and military veteran caregivers. Smith College Studies in Social Work, 79, 314-329.

Creswell, J. (2007). Qualitative inquiry and research design: Choosing among five approaches (2nd ed.). Thousand Oaks, CA: Sage.

Creswell, J., \& Plano Clark, V. (2007). Designing and conducting mixed methods research. Thousand Oaks, CA: Sage.

Dekel, R., Goldblatt, H., Keidar, M., Solomon, Z., \& Polliack, M. (2005). Being a wife of a veteran with posttraumatic stress disorder. Family Relations, 54, 24-36. Retrieved from http://onlinelibrary.wiley.com/journal/10.1111/\%28ISSN\%291741-3729

Dekel, R., \& Solomon, Z. (2006). Secondary traumatization among wives of Israeli POWs: The role of POW' distress. Social Psychiatry and Psychiatric Epidemiology, 41, 27-33.

Dirkzwager, A., Bramsen, I., Ader, H., \& van der Ploeg, H. (2005). Secondary traumatization in partners and parents of Dutch peacekeeping soldiers. Journal of Family Psychology, 19, 217 226. doi:10.1037/0893-3200.19.2.217

Drummet, A., Coleman, M., \& Cable, S. (2003). Military families under stress: implications for family life education. Family 52, 279-287. doi:10.1111/j.1741-3729.2003.00279.x

Galovski, T., \& Lyons, J. A. (2004). Psychological sequelae of combat violence: A review of the impact of PTSD on the veteran's family and possible interventions. Aggression and Violent Behavior, $9,477-501$.

Heinrich, L., \& Gullone, E. (2006). The clinical significance of loneliness: A literature review. Clinical Psychology Review, 26, 695-718

Hofmann, S., Litz, B., \& Weathers, F. (2003) Social anxiety, depression, and PTSD in Vietnam Veterans. Anxiety Disorders, 17(1), 573-582. Retrieved from http://www.journals.elsevier.com/journal-of-anxiety-disorders/

Jordan, B. K., Marmar, C. R., Fairbank, J. A., Schlenger, W. E., Kulka, R. A., Hough, R. L., \& Weiss, D. S. (1992). Problems in families of male Vietnam veterans with posttraumatic stress disorder. Journal of Consulting and Clinical Psychology, 60, 916-926.

Klarić, M., Frančišković, T., Pernar, M., Moro, I., Milićević, R., Obrdalj, E., \& Satriano, A. (2009). Caregiver burden and burnout in partners of war veterans with posttraumatic stress disorder. Collegium Antropologicum, 34, 15-21. Retrieved from http://www.collantropol.hr/antropo

Lorig, K., Thompson-Gallagher, D., Traylor, L., Ritter, P. L., Laurent, D. D., Plant, K., . . Hahn, T. J. (2010). Building better caregivers: A pilot online support workshop for family caregivers of cognitively impaired adults. Journal of Applied Gerontology, 31, 423-437. 
Matsakis, A. (1996). Vietnam wives: Facing the challenges of life with veterans suffering posttraumatic stress (2 ${ }^{\text {nd }}$ Ed., Rev.). Baltimore, MD: The Sidran Press.

Merriam, S. (2009). Qualitative research: A guide to design and implementation. San Francisco, CA: Jossey Bass.

Monson, C., Taft, C., \& Fredman, S. (2009). Military-related PTSD and intimate relationships: From description to theory-driven research and intervention development. Clinical Psychology Review, 29, 707-714. doi:10.1016/j.cpr.2009.09.002

Moustakas, C. (1994). Phenomenological research methods. Thousand Oaks, CA: Sage.

Outram, S., Hansen, V., Macdonell, G., Cockburn, J., \& Adams, J. (2009). Still living in a war zone: Perceived health and wellbeing of partners of Vietnam veterans attending partners' support groups in New South Wales, Australia. Australian Psychologist, 44, 128-135. doi:10.1080/0005006080263053

Peplau, L. A., \& Perlman, D. (1982). Perspectives on loneliness. In L. A. Peplau \& D. Perlman (Eds.), Loneliness: A sourcebook of current theory, research and therapy (pp. 1-18), New York, NY: Wiley-Interscience Publication

Sherman, M., Perlick, D., \& Straits-Tröster, K. (2005). Adapting the multi-family group model for treating veterans with posttraumatic stress disorder. Psychological Services, 1, 1-12. doi:10.1037/a0028963

Solomon, Z., \& Dekel, R. (2008). The contribution of loneliness and posttraumatic stress disorder to marital adjustment following war captivity: A longitudinal study. Family Process, 47, 261275. Retrieved from http://onlinelibrary.wiley.com/journal/10.1111/\%28ISSN\%291545-5300

Taft, C., Street, A., Marshall, A., Dowdall, D., \& Riggs, D. (2007). Posttraumatic stress disorder, anger, and partner abuse among Vietnam combat veterans. Journal of Family Psychology, $21,270-277$

Weiss, R. (1973). Loneliness: The experience of emotional and social isolation. Cambridge, MA: MIT Press.

(Appendix follows) 


\section{Appendix}

\section{Interview Questions}

1. I am interested in knowing about your relationships with your friends and family. Do you have any friends separate from your partner?

a. How often do you see them, and what do you do in your time together?

b. How often do you see your family?

c. Do you see them alone or with your veteran?

2. You indicated that your partner with PTSD isolates himself socially; how does this social isolation affect you?

3. How would you describe your satisfaction with your social life overall?

a. Tell me what makes your social life work.

b. Tell me what would make your social life better?

4. Are you satisfied with your social life with your friends?

a. Tell me about your social life involving friends.

b. How do you maintain your social relationships with friends?

c. Tell me what you do to cope with changes in how you socialize with your friends?

5. Are you satisfied with your social life involving family?

a. Tell me about your social life involving family.

b. How do you maintain your social relationships with family?

c. Tell me what you do to cope with changes in how you socialize with your family.

Regarding your perception of available resources for receiving mental health services for you:

6. Have you considered using any professional resources within the past year?

7. Would you use any other community or professional supports if they were available to you?

a. Tell me about what you would use.

8. Have you used any support groups?

a. If so, what did it do for you? If not, why not? 
The Journal of Social, Behavioral, and Health Sciences is an open-access, peer-reviewed, online interdisciplinary journal focusing on research findings that address contemporary national and international issues. Its objectives are to (a) encourage dialogue between scholars and practitioners in the social, behavioral, and health sciences that fosters the integration of research with practice; (b) promote innovative models of interdisciplinary collaboration among the social, behavioral, and health sciences that address complex social problems; and (c) inform the relationship between practice and research in the social, behavioral, and health sciences.

Walden University Publishing: http://www.publishing.waldenu.edu 